\title{
Simultaneous Free Radical and Addition Miniemulsion \\ Polymerization: Effect of the Diol on the Microstructure of Polyurethane-Acrylic Pressure-Sensitive Adhesives.
}

Aitziber Lopez $^{a}$, Elise Degrandi ${ }^{b, c}$, Elisabetta Canetta ${ }^{d, e}$, Joseph. L. Keddie $^{d}$, Costantino Creton ${ }^{b}$, José M. Asua ${ }^{a *}$

${ }^{a}$ Institute for Polymer Materials, POLYMAT, and Grupo de Ingeniería Química, Dpto. de Química Aplicada, Facultad de Ciencias Químicas, University of the Basque Country, Joxe Mari Korta zentroa, Tolosa Etorbidea 72, 20018 Donostia-San Sebastián, Spain

${ }^{\mathrm{b}}$ Laboratoire de Physico-Chimie des Polymères et Milieux Dispersés, ESPCI, CNRS, 10 Rue Vauquelin, F-75231 Paris Cédex 05, France

${ }^{c}$ Current address: Laboratoire de Physique des Solides, Université Paris sud, UMR CNRS 8502, Bat. 510, Campus d'Orsay, 91405 Orsay cedex, France

dDepartment of Physics, Faculty of Engineering and Physical Sciences, University of Surrey, Guildford, Surrey GU2 7XH, England, UK

${ }^{\mathrm{e}}$ Current address: School of Physics and Astronomy, University of St. Andrews, St. Andrews, Fife KY16 9SS, Scotland, UK

aitziber.lopez@ehu.es; Elise.Degrandi@espci.fr; ec210@st-andrews.ac.uk; J.Keddie@surrey.ac.uk; Costantino.Creton@espci.fr; jm.asua@ehu.es

\begin{abstract}
Water-borne polyurethane/acrylic hybrid latexes for their application as pressure-sensitive adhesives were prepared by high solids simultaneous free radical and addition miniemulsion polymerization. In these polymerizations, the polymer network was formed by polyurethane chains that were linked to acrylic chains by the joint reaction of a hydroxyl functional methacrylate and an isocyanate functional polyurethane prepolymer, and by acrylic chains linked among themselves. Under the working conditions, the modification of the polymer architecture was possible by altering the acrylic chains, the polyurethane chains and the links between the polyurethane and the acrylic chains. In the present work, the polymer microstructure was modified by the addition of different diols (polyurethane chain extenders) to the formulation. The effect of the nature of the diol on polymerization kinetics, polymer microstructure and adhesive performance of water-borne PSAs was studied. Adhesive test results demonstrate clearly for the first time that the long term resistance to shear of an acrylic PSA does not depend only on its gel content but very much depends on the detailed microstructure of the gel inside each particle.
\end{abstract}

* To whom correspondence should be addressed: E-mail: jm.asua@ehu.es. Telephone: (+34) 943018181. Fax: (+34) 9430017065. 


\section{Keywords}

Polyurethane, acrylic, hybrid, pressure-sensitive adhesive, diol, miniemulsion, microstructure, adhesive properties.

\section{Introduction}

Pressure-sensitive adhesives (PSAs) are a distinct type of materials that adhere instantly and firmly to a variety of surfaces under the application of light pressure [1]. They are typically composed of a very viscoelastic, entangled and lightly crosslinked polymer network with a low glass transition temperature and an elastic modulus in the range of $10-100 \mathrm{kPa}$. The most common PSA applications are in tapes, labels and protective films, but they are also used in the automotive, aerospace and electronic industries [2]. They are manufactured as hot-melt, solvent-borne and water-borne materials, but due to environmental regulations, water-borne PSAs are gaining market share even in demanding applications. This, in turn, requires a better understanding of the structure/properties relationship for water-borne systems.

Water-borne acrylic pressure-sensitive adhesives (PSAs) are very popular because of their excellent balance between the end-product properties, the compatibility with different additives and their processability $[3,4]$. A major disadvantage of the water-borne PSAs is that they often have low cohesive strength $[5,6]$. This failure is particularly noticeable at high temperatures [7]. The introduction of polyurethane (PU) in the water-borne acrylic - PSAs is expected to increase the shear strength in two main ways: the polar groups of the polyurethane may form hydrogen bonds with each other, and the polyether soft segments can increase the entanglement density because of their low entanglement molecular weight.

There are different ways of incorporating PUs into water-borne acrylic PSAs. The simplest way is by blending PU dispersions with acrylic latexes. However, the incompatibility between the PU and the acrylic polymers causes a phase separation, hindering the desired synergy of properties in the final product [8-11]. Phase separation may be avoided by chemically bonding the two polymers, i.e., by polymerizing acrylic monomers in the presence of a vinyl functionalized PU [12-17]. This is a 
two-step process in which vinyl groups are first incorporated to the PU and then the free radical polymerization of the acrylic monomers is performed. However, this approach offers limited possibilities to control the molecular architecture, and hence, the adhesive properties of the hybrid, because the polymer is the result of a free radical polymerization carried out in the presence of a crosslinker, which closely resembles the system studied by Chauvet et al. [18, 19].

A different way of producing PU-acrylic PSAs is to polymerize, in the presence of an isocyanate terminated PU and of a chain extender, a mixture of acrylic monomers, at least one of them containing a functional group able to react with the isocyanate groups of the PU. In this way, the polymer is formed by simultaneous free radical and addition polymerizations.

Hydroxyl, amino and glycidyl groups are examples of functional groups able to react with the isocyanate groups of the PU. In the present work, 2-hydroxyethyl methacrylate (2-HEMA) has been used. Diamines [20-22] and diols [22, 23] are often used as chain extenders in the synthesis of polyurethane dispersions. In the present work, the choice of the chain extender was determined by its reactivity. As polyaddition and radical polymerization occurred simultaneously, the reactivity of the chain extender with the isocyanate terminated polyurethane prepolymer should be similar to or lower than the reactivity of the hydroxyl groups of the 2-hydroxyethyl methacrylate (2-HEMA), because the incorporation/crosslinking of PU was essential for the purpose of this work. As a consequence, diols were chosen as chain extenders. It is important to point out that the extension of the isocyanatewater reaction (foaming reaction) should be minimized in order to avoid the loss of isocyanate equivalents. As the reactivity of the diols is similar to that of the water, dibutyltin dilaurate (DBTDL) was added as a catalyst to promote the isocyanate-hydroxyl reaction with respect to the reaction with water [24]. Moreover, because of its hydrophobic character, DBTDL is preferably located in the monomer droplets, making the reaction with alcohols more effective [15].

The architecture of the PU-acrylic polymers may be affected by modifying the acrylic chains, the polyurethane chains and the links between the polyurethane and the acrylic chains. In this work, the polymer architecture was modified by changing the polyurethane chains by using different diols: 1,6-hexanediol, 1,4-cyclohexanediol and bisphenol A. To our best knowledge, the effect of the chain 
extenders on either polymer microstructure or the properties of polyurethane/acrylic hybrids has not been investigated. Li et al. [16] analyzed the effect of the hydrophobic/hydrophilic nature of different chain extenders on both the particle size and the stability of PU/acrylic hybrid coatings produced by miniemulsion polymerization. However, the effect of the chain extenders on the polymer architecture and the final properties was not reported. The hybrid PSAs were synthesized by semicontinuous miniemulsion polymerization.

\section{Experimental Section}

2.1. Materials. Incorez 701 urethane prepolymer was supplied by Incorez Ltd. (Preston, England). Incorez 701 is a $100 \%$ solids content reactive urethane prepolymer based on an aliphatic isocyanate (IPDI) and a polyether, specially designed for adhesive applications. The equivalent weight of the prepolymer is $1050 \mathrm{~g} /$ equivalent, and the NCO concentration is ca. $4.0 \mathrm{~mole} \%$. The prepolymer was used without any further purification.

Technical grade monomers, 2-ethylhexyl acrylate (2-EHA, Quimidroga), methyl methacrylate (MMA, Quimidroga), methacrylic acid (MAA, Aldrich), 2-hydroxyethyl methacrylate (2-HEMA, Aldrich) and stearyl acrylate (SA, Aldrich) were likewise used without further purification. SA played the role of a reactive costabilizer in order to avoid the Ostwald Ripening phenomenon [25]. Bisphenol A, 1,6-hexanediol and 1,4-cyclohexanediol (all of them supplied by Aldrich) were used as chain extender agents for the urethane prepolymer, and dibutyltin dilaurate (DBTDL, Aldrich) was used as a catalyst for the addition reaction. Alkyl diphenyloxide disulfonate (Dowfax 2A1, Dow Chemical) was the main surfactant used in the preparation of the miniemulsion, and sodium dodecyl sulfate (SDS, Aldrich) was post-added in order to improve the miniemulsion stability. Potassium persulfate (KPS, Fluka) was used as the initiator for the free radical polymerization. Sodium bicarbonate $\left(\mathrm{NaHCO}_{3}\right.$, Fluka) was added to the formulation in order to decrease the viscosity of the miniemulsions. Doubly deionized water (DDI) was used throughout the work. 
Table 1. Formulation used in the study of the effect of the diol on both the polymer microstructure and the adhesive properties.

\begin{tabular}{|c|c|c|}
\hline Ingredient & Amount (g) & $\mathrm{wt} \%$ \\
\hline 2-EHA & 392.85 & $93.27^{\mathrm{a}}$ \\
\hline MMA & 6.07 & $1.44^{\mathrm{a}}$ \\
\hline MAA & 4.05 & $0.96^{\mathrm{a}}$ \\
\hline 2-HEMA & 2.03 & $0.48^{\mathrm{a}}$ \\
\hline SA & 16.20 & $3.85^{\mathrm{a}}$ \\
\hline Incorez 701 & 45.00 & $9.65^{\mathrm{b}}$ \\
\hline Chain extender & $\left\{\begin{array}{c}1,6 \text {-hexanediol } 4.14 \\
1,4 \text {-cyclohexanediol } 4.04 \\
\text { bisphenol A } 7.86\end{array}\right\}$ & Amount for having $\mathrm{OH} / \mathrm{NCO}=2$ \\
\hline DBTDL & 0.22 & $465 \mathrm{ppm}^{\mathrm{c}}$ \\
\hline Dowfax $2 \mathrm{~A} 1$ & $18.00(45 \mathrm{wt} \%$ active $)$ & $1.73^{b}$ \\
\hline $\mathrm{NaHCO}_{3}$ & 0.73 & $0.02 \mathrm{M}^{\mathrm{d}}$ \\
\hline DDI water & 350.0 & 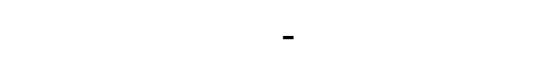 \\
\hline
\end{tabular}

Batch 0.19

KPS

Feed 0.75

$0.48^{\mathrm{a}}$

(3.16 wt $\%$ aqueous solution)

a) Weight based on monomer weight (wbm)

b) Weight based on organic phase weight (wbo)

${ }^{\text {c) }}$ ppm based on organic phase

d) Based on water phase

2.2. Miniemulsification. The formulation used is presented in Table 1 . The organic phase, composed by the acrylic monomers, the PU prepolymer (Incorez 701), the chain extender and the catalyst (dibutyltin dilaurate, DBTDL); and the aqueous phase, containing the emulsifier (Dowfax 
2A1) and $\mathrm{NaHCO}_{3}$, were mixed under magnetic stirring for 15 minutes at $750 \mathrm{rpm}$. The resulting mixture was first sonicated (15 minutes at 9 output control and $80 \%$ duty cycle) and finally homogenized for 4 cycles in a two-valves high pressure homogenizer (Manton Gaulin APV Lab 60.10 in a loop arrangement or Niro Soavi Panda $2 \mathrm{~K}$ in a in-line arrangement). The pressure in the first valve was 41.3 $\mathrm{MPa}$ and in the second valve, 4.13 $\mathrm{MPa}$. After miniemulsification, $0.87 \mathrm{wt} \%$ (weight based on organic phase) sodium dodecyl sulfate (as a $6.5 \mathrm{wt} \%$ solution of SDS in DDI water) was added to the dispersion in order to increase its colloidal stability.

2.3. Polymerization process. The semicontinuous miniemulsion polymerizations were carried out at $80{ }^{\circ} \mathrm{C}$ in a $750 \mathrm{~mL}$ glass reactor fitted with a reflux condenser, a sampling device, a nitrogen inlet, two feeding inlets, a thermometer and a stainless steel anchor type stirrer rotating at $250 \mathrm{rpm}$.

$20 \mathrm{wt} \%$ of the miniemulsion ( $52 \mathrm{wt} \%$ organic phase) was used as initial charge. When the reaction temperature reached $80^{\circ} \mathrm{C}, 0.48 \mathrm{wt} \%(\mathrm{wbm})$ of potassium persulfate (KPS, as a $3.16 \mathrm{wt} \%$ aqueous solution) was added as a shot and the miniemulsion was allowed to polymerize in batch for 1 hour. Then, the rest of the miniemulsion and $0.48 \mathrm{wt} \%$ (wbm) of KPS (as a $3.16 \mathrm{wt} \%$ aqueous solution) were fed over 3 hours. After this period, the reaction temperature was maintained for 2 additional hours. The final solids content of the latexes was around $48-49 \mathrm{wt} \%$. Samples were withdrawn at regular intervals from the reactor and the polymerization was short-stopped with hydroquinone.

2.4. Characterization. Z-average diameters of the miniemulsion droplets and polymer particles were measured by dynamic light scattering (Zetasizer Nano Z, Malvern Instruments). Samples were prepared by diluting a fraction of the latex or miniemulsion with deionized water (saturated with monomer in the case of the miniemulsion droplets). The number of particles $\left(\mathrm{N}_{\mathrm{p}}\right)$ and droplets $\left(\mathrm{N}_{\mathrm{d}}\right)$ were calculated from the light scattering average diameters taking into account the unreacted monomer concentration, the acrylic polymer and the concentration of Incorez 701. As $\mathrm{N}_{\mathrm{p}}$ and $\mathrm{N}_{\mathrm{d}}$ were calculated using the third power of the sizes measured by DLS, they are affected by some uncertainty.

The conversion of the acrylic monomers was determined gravimetrically and it was calculated with respect to the monomer, i.e., the amount of Incorez 701 was not taken into account. The 
instantaneous conversion was defined as the amount of acrylic polymer divided by the total amount of acrylic monomer fed until that time. The overall conversion was defined as the amount of acrylic polymer divided by the total amount of acrylic monomer in the formulation.

The gel content was measured gravimetrically after 24 hours of soxhlet extraction with tetrahydrofuran (THF). Glass fiber square pads (CEM) were used as backing. 10-15 drops of latex were deposited on the filter (weight $=\mathrm{W}_{1}$ ) and dried overnight. The filter plus the dried polymer were weighed (weight $=\mathrm{W}_{2}$ ) before performing a continuous extraction with THF under reflux in the soxhlet for 24 hours. Finally, the filter was dried overnight and the weight of the dry sample was registered (weight $=\mathrm{W}_{3}$ ). The gel content was calculated as the ratio between the weight of the insoluble fraction and that of the initial sample, as shown in eq. (1).

$$
\text { Gel content } \%=\frac{\left(W_{3}-W_{1}\right)}{\left(W_{2}-W_{1}\right)} \times 100
$$

To measure the swelling capability, the latexes were first coagulated at $60{ }^{\circ} \mathrm{C}$ using a $\mathrm{CaCl}_{2}$ aqueous solution $\left(2 \mathrm{wt} \% \mathrm{CaCl}_{2}\right)$ and the coagulum was dried in a ventilated oven at $60{ }^{\circ} \mathrm{C}$ for two days.. In a first step, a system composed by metallic grids with different pore sizes (called box) was weight (weight $=\mathrm{W}_{1}$ ), immersed in a $100 \mathrm{ml}$ beaker glass containing $75 \mathrm{ml}$ of THF, and placed in a THF saturated dessicator. After 30 minutes the box was taken out the beaker and let drained in the dessicator for another 30 minutes. The humidified box was weighed (weight $=\mathrm{W}_{2}$ ) and dried in a ventilated oven at $60{ }^{\circ} \mathrm{C}$ for 3 hours. In a second step, about $0.5 \mathrm{~g}$ of coagulum was placed into the dry box, immersed again in the solvent and placed in the dessicator for 24 hours. After this period, the box was taken out from the solvent and drained in the dessicator for another hour. The humidified box and swollen gel were weighed (weight $=\mathrm{W}_{3}$ ) and dried in a ventilated oven at $60{ }^{\circ} \mathrm{C}$ overnight. Finally, the dried box and gel polymer were again weighed (weight $=\mathrm{W}_{4}$ ). The swelling capability was determined as the ratio between the weight of the swollen gel and the gel fraction (eq. 


$$
\text { Swelling capability }=\frac{\left(W_{3}-W_{2}\right)}{\left(W_{4}-W_{1}\right)}
$$

The swelling capability was used to calculate the average molecular weight between crosslink points $\left(\mathrm{M}_{\mathrm{c}}\right)$ by means of the Flory-Rehner equation [26, 27]:

$$
M_{c}=\frac{\rho_{2} V_{1}\left(\phi_{2}^{1 / 3}-\phi_{2} / 2\right)}{\ln \left(1-\phi_{2}\right)+\phi_{2}+\chi_{12} \phi_{2}^{2}}
$$

where $\rho_{2}$ the density of the polymer, $V_{1}$ the molar volume of the solvent (in this case THF), $\Phi_{2}$ is the volume fraction of the swollen polymer and $\chi_{12}$ the Flory-Huggins interaction parameter. $\Phi_{2}$ was calculated as follows:

$$
\phi_{2}=\frac{1}{1+\frac{\rho_{2}}{\rho_{1}}\left(\frac{m_{a}}{m_{b}}\right)-\frac{\rho_{2}}{\rho_{1}}}
$$

where $\rho_{l}$ is the THF density, $m_{a}$ the mass before swelling and $m_{b}$ the mass after swelling with THF.

On the other hand, $\chi_{12}$ was calculated using the solubility parameters ( $\delta$ ) of Poly(2-EHA) (1) and THF (2) at $20^{\circ} \mathrm{C}$.

$$
\chi_{12}=0.34+\frac{V_{1}}{R T}\left(\delta_{1}-\delta_{2}\right)
$$

with $\delta_{1}=18.37 \mathrm{MPa}^{0.5}$ and $\delta_{2}=19.44 \mathrm{MPa}^{0.5}[28]$.

The molecular weight of the sol (obtained by soxhlet extraction) was determined by Size Exclusion Chromatography/Gel Permeation Chromatography (SEC/GPC). The samples taken out from the soxhlet were first dried, redissolved in THF to achieve a concentration of about $0.1 \%$ $(\mathrm{g} / \mathrm{ml})$ and filtered (polyamide $\Phi=45 \mu \mathrm{m})$ before injection into the SEC instrument. The set up consisted of a pump (LC-20A, Shimadzu), an autosampler (Waters 717), a differential refractometer (Waters 2410) and three columns in series (Styragel HR2, HR4 and HR6, with pore sizes ranging from $10^{2}$ to $10^{6} \AA$ ). Chromatograms were obtained at $35^{\circ} \mathrm{C}$ using a THF flow rate of $1 \mathrm{ml} / \mathrm{min}$. The equipment was calibrated using polystyrene standards $\left(5^{\text {th }}\right.$ order universal calibration) and therefore the molecular weight was referred to PS (no Mark-Houwink constants for the polyurethane/acrylic hybrid polymers were available). 
2.5. Atomic Force Microscopy. The particle morphology was analyzed with atomic force microscopy (AFM) (NTEGRA NT-MDT, Moscow, Russia). Individual latex particles were imaged in the semi-contact mode. Latexes were diluted 100 times in deionised water and then spin-coated at $4000 \mathrm{rpm}$ onto $1 \mathrm{~cm} \mathrm{x} 1 \mathrm{~cm}$ sheets of freshly-cleaved mica. Silicon cantilevers (ATEC-NC, Nanosensors, Switzerland) with a nominal spring constant of $k=45 \mathrm{~N} / \mathrm{m}$ and a high resonance frequency $(330 \mathrm{kHz})$ were used. All the AFM experiments were performed in air at room temperature, and the height and phase images were acquired using a scan rate of $1.56 \mathrm{~Hz}$.

2.6. Adhesive properties. Adhesive performance was measured in terms of loop tack, peel resistance, static shear resistance at $70{ }^{\circ} \mathrm{C}$ (holding power shear test) and shear adhesion failure temperature (SAFT).

For sample preparation, latexes were first neutralized with ammonia. For loop tack and peel resistance measurements, films were prepared using an electrostatic discharge-treated $29 \mu \mathrm{m}$ thick polypropylene (PP) film as backing. Over this backing, a $120 \mu \mathrm{m}$ wet film was applied and dried first at $23^{\circ} \mathrm{C}$ and $55 \%$ of humidity for 30 minutes and heated at $60^{\circ} \mathrm{C}$ for additional half and hour. The final dry film was around 50-60 $\mu \mathrm{m}$ thick. Films of the same thicknesses were prepared for shear resistance and SAFT measurements but using $23 \mu \mathrm{m}$ Mylar® Polyester PET film as backing.

For loop tack experiments, the coated adhesive was folded to form a loop with the adhesive facing outwards. The loop was clamped to the top jaw of an Instron equipment leaving the loop hanging vertically downwards. The loop was positioned in contact with the surface (stainless steel, SS) at a speed of $300 \mathrm{~mm} / \mathrm{min}$ until obtaining full contact $(2.5 \mathrm{~cm}$ x $2.5 \mathrm{~cm})$. Immediately after, the direction of the machine was reversed at a crosshead velocity of $300 \mathrm{~mm} / \mathrm{min}$ [29]. The value of the loop tack was averaged for five tests per latex. The type of detaching, adhesive (without leaving any residue in the SS) or cohesive (leaving residues in the SS) was also recorded.

The peel resistance tests were performed using a $180^{\circ}$ angle and a $300 \mathrm{~mm} / \mathrm{min}$ speed [30] in Instron equipment. A $2.5 \times 8 \mathrm{~cm}$ sample was applied to a standard stainless steel panel using a given pressure ( $2 \mathrm{~kg}$ roller, 4 times) to make the contact and the tests were conducted after 20 minutes of the bonding. The adhesion value was the average peel force obtained during the peeling process. The 
final value was calculated as the average of 4 measurements per latex. The initial peel values were disregarded.

Shear resistance at $70^{\circ} \mathrm{C}$ and SAFT were measured by the shear holding power test [31] in a SAFT oven. The shear resistance measurement consisted in applying under pressure a standard area of tape $(2.5 \mathrm{~cm} \times 2.5 \mathrm{~cm})$ over the testing substrate (stainless steel) and applying a standard weight $(1 \mathrm{~kg})$ until failure. Before starting the tests, the samples were allowed to be at $70{ }^{\circ} \mathrm{C}$ during 15 minutes. SAFT over stainless steel was measured using a temperature ramp of $1{ }^{\circ} \mathrm{C} / \mathrm{min}$ from $70{ }^{\circ} \mathrm{C}$ to $210^{\circ} \mathrm{C}$. In this case, before starting the tests, the samples were first kept at $30^{\circ} \mathrm{C}$ for 24 hours and then 15 minutes at $70{ }^{\circ} \mathrm{C}$.

For tensile tests and linear viscoelastic properties measurements, $500 \mu \mathrm{m}$ thick films were prepared by drying first the latexes at ambient temperature for 1 week and then heating them for 5 minutes at $110^{\circ} \mathrm{C}$. Tensile test experiments were carried out in a standard tensile Instron equipment (5565) equipped with a videoextensometer (SVE) and a $10 \mathrm{~N}$ load cell at $15 \mathrm{~mm} / \mathrm{s}$ crosshead velocity, which corresponded to $1 \mathrm{~Hz}$ nominal strain rate. The linear viscoelastic properties of the adhesive layers were carried out with a standard fixed displacement rheometer (RDAII from TA Instrument) in a parallel-plate geometry and a diameter of $8 \mathrm{~mm}$. Circular samples of $8 \mathrm{~mm}$ diameter were cut from the films. Experiments were performed at $30{ }^{\circ} \mathrm{C}$ and a deformation of $8 \%$ was imposed on the samples to remain in the linear strain regime.

\section{Results and Discussion}

\subsection{Polymerization kinetics and microstructure}

The sizes of the miniemulsion droplets formulated with different diols and measured by dynamic light scattering are presented in Table 2 . It can be seen that the diols did not significantly affect the droplet size. 
Table 2. Effect of the diol on the Z- average droplet size.

\begin{tabular}{cc}
\hline Chain extender & $\mathrm{d}_{\mathrm{d}}(\mathrm{nm})$ \\
\hline 1,6-hexanediol & 150 \\
1,4-cyclohexanediol & 156 \\
bisphenol A & 149
\end{tabular}

In order to check the occurrence of the isocyanate-diol and/or the isocyanate-water reaction during the miniemulsification and/or the storage, the molecular weight distribution of the PU contained in the miniemulsions was determined at different times. Figure 1 shows that, in the case of 1,6hexanediol, no variation was observed over 8 hours. The same behavior was observed in the miniemulsions prepared with 1,4-cyclohexanediol and bisphenol A. Because the miniemulsions were kept at room temperature, this does not mean that these reactions were negligible under polymerization conditions, but it shows that no reaction occurred during the time elapsed from the preparation of the miniemulsion to the moment in which it was fed to the reactor.

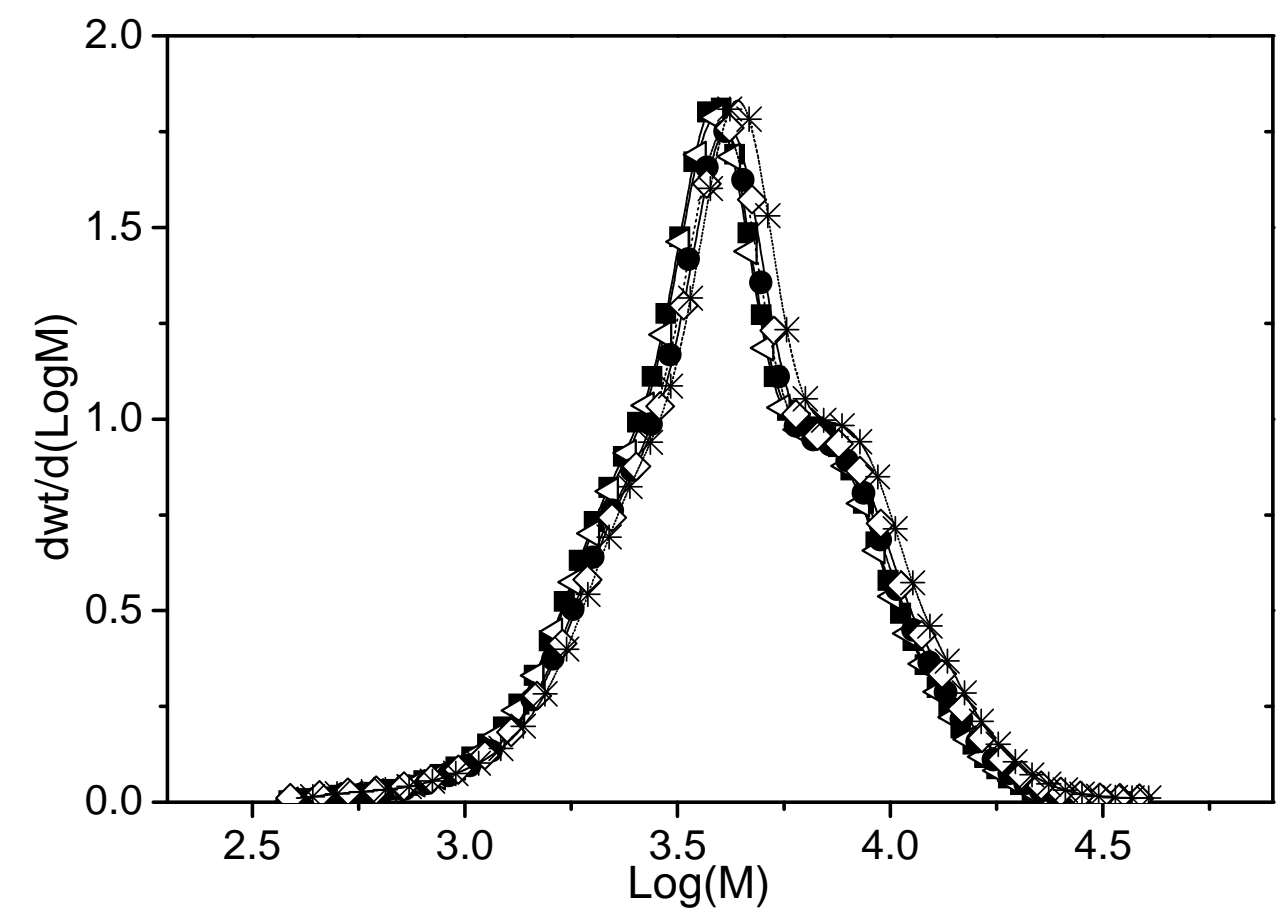

Figure 1. Molecular weight distribution of the Incorez 701 contained in the miniemulsions measured at different times when1,6-hexanediol was used as a chain extender.

( Incorez 701; Miniemulsions: $\triangleleft \mathrm{t}=0$ hours; $\mathrm{t}=2$ hours; $\diamond \mathrm{t}=4$ hours; $* \mathrm{t}=8$ hours) 
The effect of the diol on the evolution of the instantaneous monomer conversion is shown in Figure 2. Figure 3 presents the evolution of the number of particles. It can be seen that the polymerization rate was substantially lower for bisphenol A, even though the number of particles was higher. This indicates that the average number of radicals per particle $(\bar{n})$ was lower than for the other diols. On the other hand, the highest polymerization rate was observed for 1,4cyclohexanediol, which had the lowest number of particles. This means that, for this experiment, $\bar{n}$ was substantially higher than for the other diols.



Figure 2. Effect of the diol on the evolution of the instantaneous conversion. 


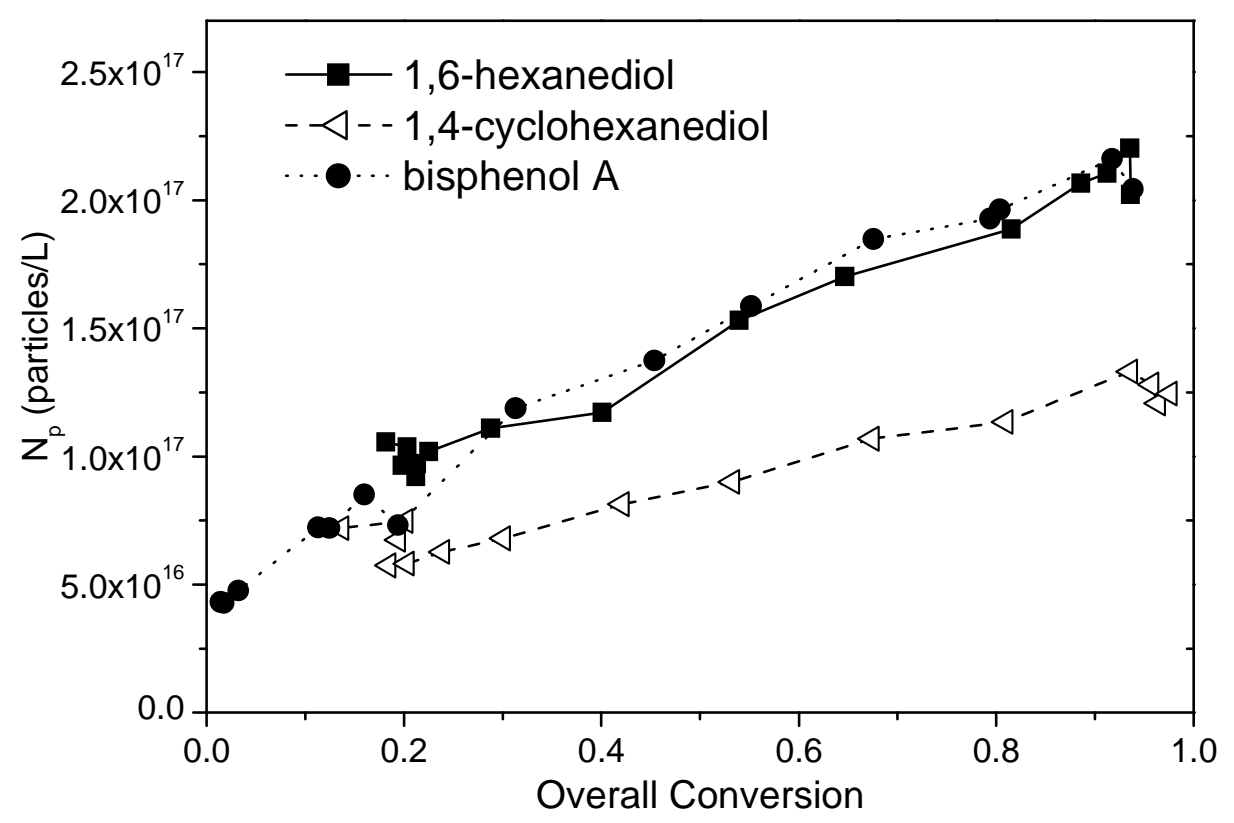

Figure 3. Effect of the diol on the evolution of the number of particles.

In order to shed light on the effect of the diols on the polymerization rate, all acrylic (93.27/0.96/0.96/0.96/3.85 2-EHA/MMA/MAA/2-HEMA/SA wt\%, wbm) miniemulsion polymerizations were carried out both in the presence and in the absence of diols. Figure 4 presents the effect of 1,4-cyclohexanediol and bisphenol A on the evolution of the conversion of the acrylic monomers. It can be seen that 1,4-cyclohexanediol did not affect the polymerization rate, whereas bisphenol A caused a severe decrease. 


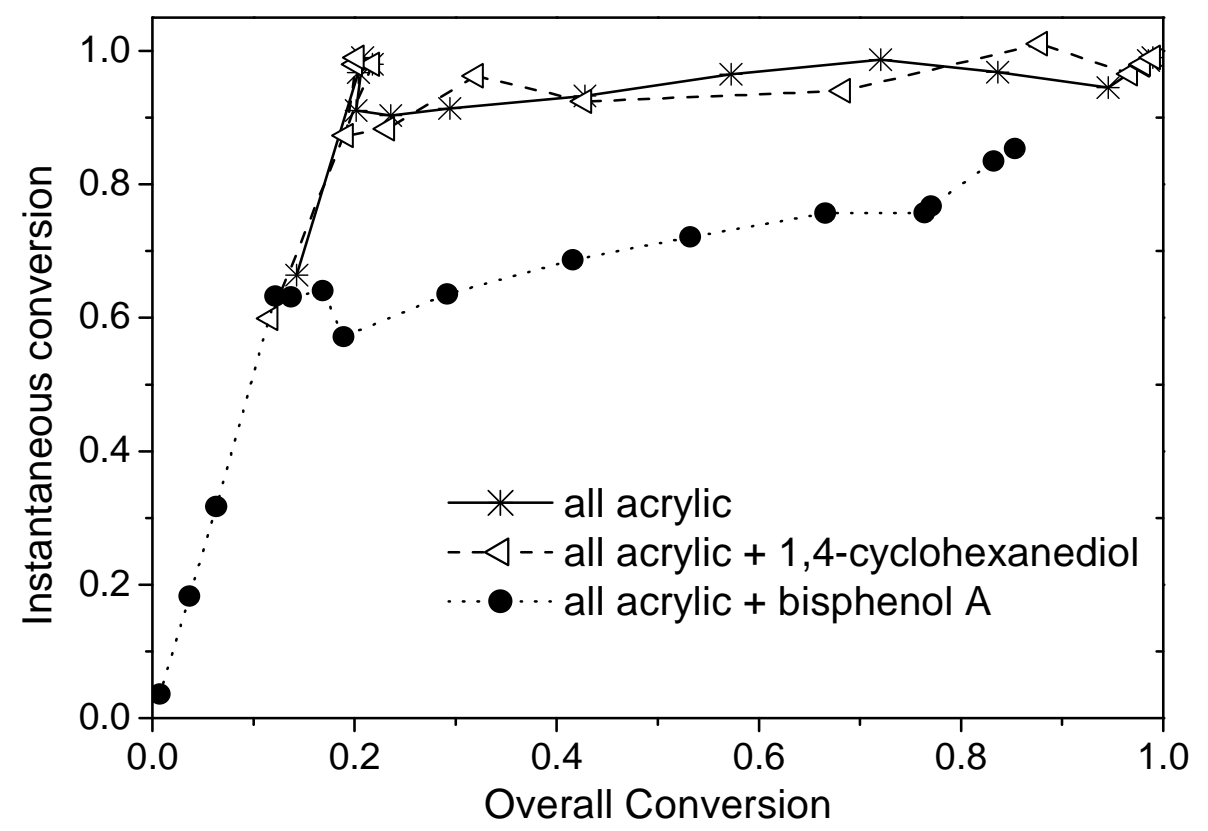

Figure 4. Effect of the diol on the acrylic monomers conversion for the all acrylic (93.27/0.96/0.96/0.96/3.85 2-EHA/MMA/MAA/2-HEMA/SA wt\%) 50 wt\% solids content miniemulsion polymerization.

Alcohols are efficient chain transfer agents [32-34], the chain transfer occurring by a hydrogen abstraction mechanism $[35,36]$. The effect of the chain transfer to alcohol on the polymerization rate depends on the reactivity of the radical formed (its capacity to re-initiate a new polymer chain) and on its water solubility. Non-reactive radicals lead to a decrease of the polymerization rate because the alcohol acts as a radical scavenger. Water-soluble radicals are prone to desorb from the polymer particles, causing a decrease in the polymerization rate.

Scheme 1 presents the radicals formed with the different diols. The stability of the radicals depends on the possibility of radical delocalization by steric or resonance mechanisms. Therefore, the stability of the radicals decreased from bisphenol A to 1,4-cyclohexanediol, and to 1,6-hexanediol. 
$\mathrm{HO}$<smiles>CCCCCCO</smiles><smiles>OC1CCC(O)CC1</smiles>

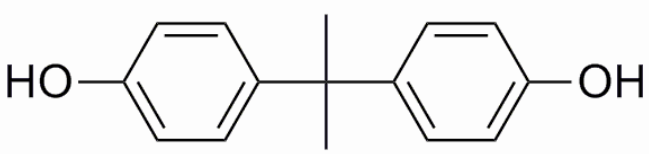<smiles>[O]CCCCCCO</smiles>
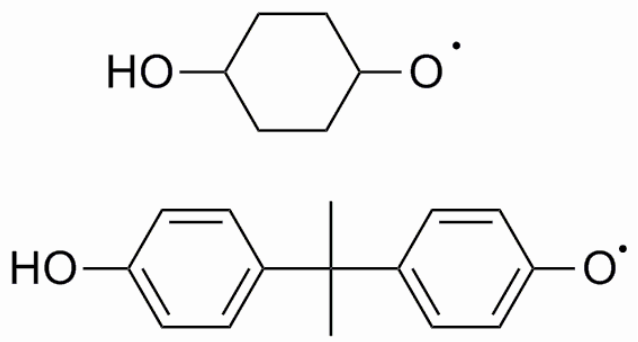

Scheme 1. The radicals formed by chain transfer to alcohol.

The radical formed from bisphenol A was very stable, i.e., it acted as a radical scavenger lowering the polymerization rate. On the other hand, Figure 4 shows that the radical formed by chain transfer to 1,4-cyclohexanediol was either very reactive or the chain transfer rate to this diol was low. Figure 5 shows that, in the all acrylic miniemulsion polymerization, the presence of 1,4-cyclohexanediol caused a decrease in the gel content. In all acrylic systems, gel is formed by intermolecular chain transfer to polymer followed by termination by combination [37]. It has been demonstrated that the decrease of the kinetic chain length, caused by chain transfer to small molecules, leads to a decrease in the gel content of the acrylates [38]. Therefore, the results in Figure 5 strongly indicate that 1,4cyclohexanediol suffered chain transfer. The lack of effect on the polymerization rate (Figure 4) indicates that the radical formed did not desorb from the polymer particles and it was reactive enough to start a new polymer chain. The case of 1,6-hexanediol is interesting because it reduced the polymerization rate. The radical formed by chain transfer to 1,6 -hexanediol is more reactive than that formed from 1,4-cyclohexanediol, therefore, the radical reactivity was not the reason for the decrease in the polymerization rate. A possible reason is that the higher water solubility of the 1,6hexanediol enhanced radical desorption, leading to a decrease in the average number of radicals per particle, and hence in the polymerization rate. 


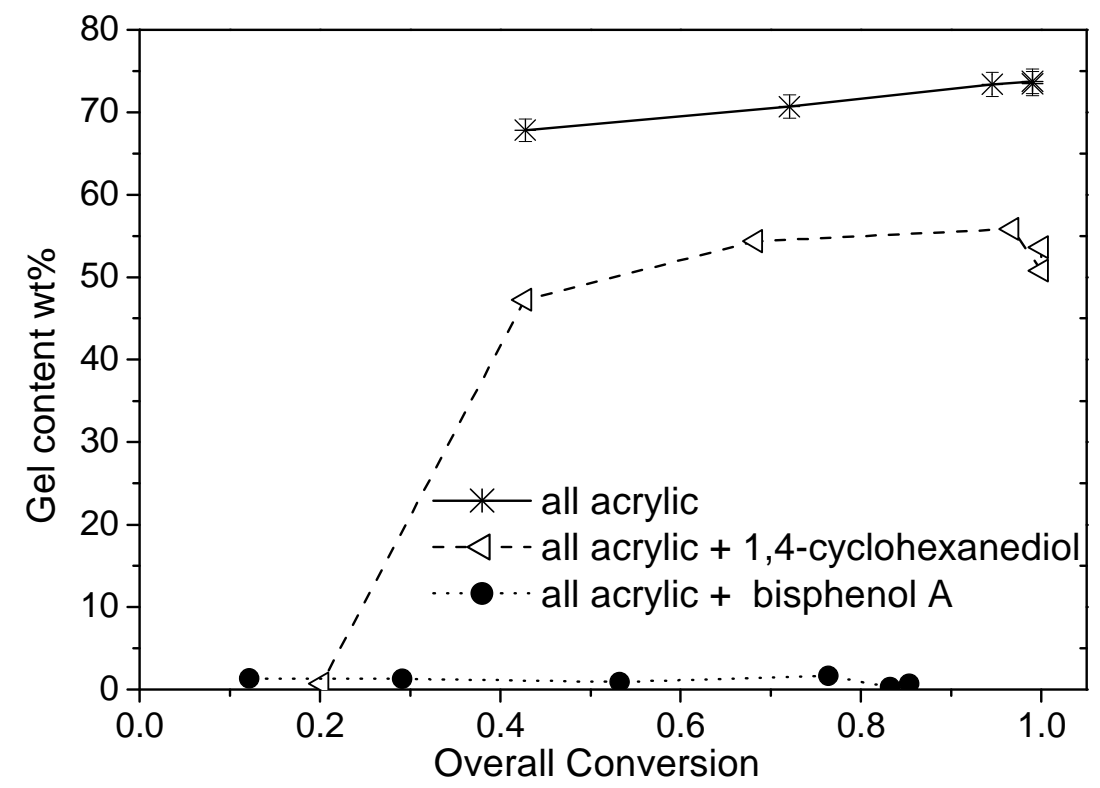

Figure 5. Effect of the diol on the evolution of the gel content in $50 \mathrm{wt} \%$ solids content all acrylics (93.27/0.96/0.96/0.96/3.85 2-EHA/MMA/MAA/2-HEMA/SA wt\%) miniemulsion polymerization.

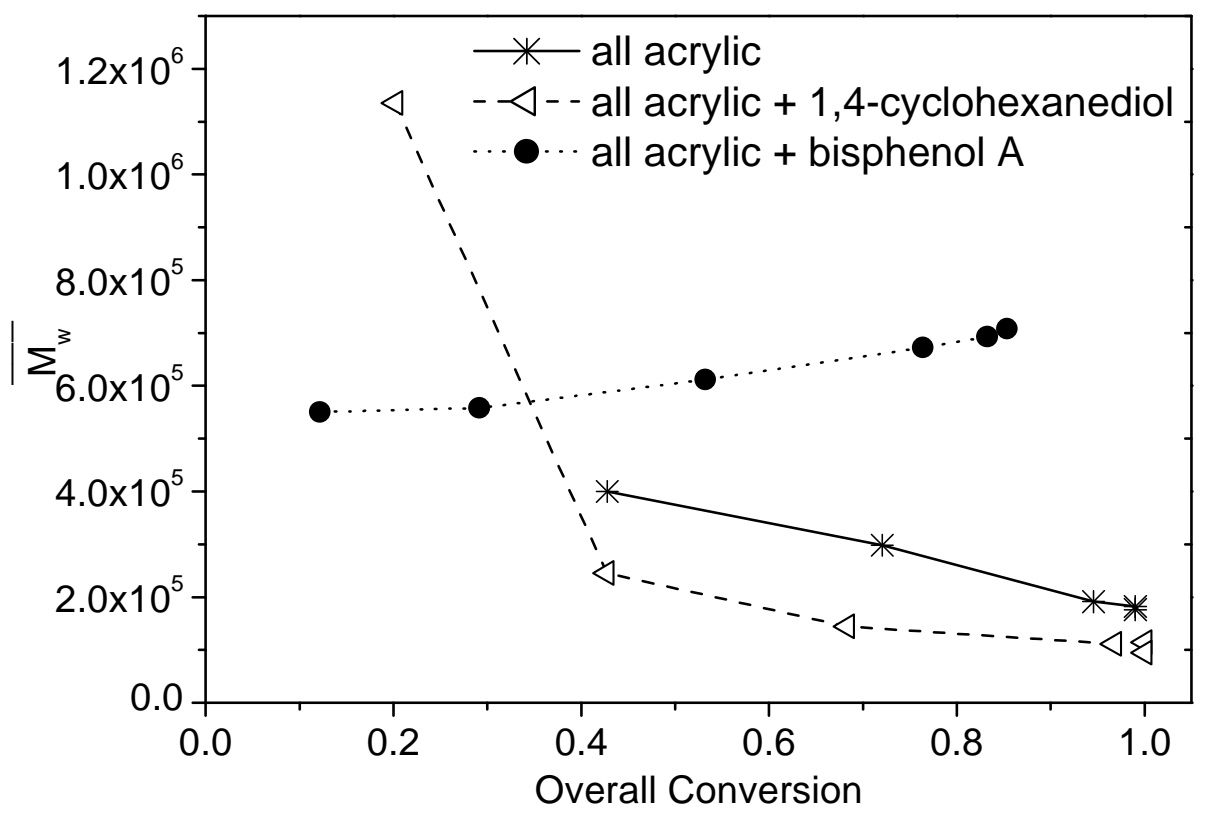

Figure 6. Effect of the diol on the evolution of the sol weight average molecular weight in the 50 wt\% solids content all-acrylic (93.27/0.96/0.96/0.96/3.85 2-EHA/MMA/MAA/2-HEMA/SA wt\%) miniemulsion polymerization. 
Figure 6 presents the effect of the nature of the diols on the evolution of the weight average molecular weight in the all-acrylic miniemulsion polymerizations. It can be seen that in the polymerization performed with bisphenol A, the sol molecular weight remained virtually constant during the whole process. Because no gel was formed, this MWD gives an indication of the kinetic chain length. Similarly, the MWD of the sample taken at overall conversion $x=0.2$ in the polymerization performed with 1,4-cyclohexanediol, which did not contain gel, contained information about the kinetic chain length in that reaction. Obviously, the fact that for acrylic monomers, termination occurs by combination and that some chain transfer to polymer may occur makes an accurate estimation of the kinetic chain length difficult from these data. Nevertheless, Figure 6 clearly shows that the kinetic chain length was shorter for bisphenol A than for 1,4cyclohexanediol, which is in agreement with the higher activity of bisphenol A as chain transfer agent. Moreover, Figure 6 shows that in the polymerization carried out with 1,4-cyclohexanediol, the molecular weight decreased sharply from $\mathrm{x}=0.2$ to $\mathrm{x}=0.4$, and more slowly for $\mathrm{x}>0.4$. From this point, the evolution of the molecular weight was similar to that obtained in the absence of diol. The reason for the decrease of the sol molecular weight was that the longer polymer chains were incorporated to the gel through intermolecular chain transfer and termination by combination [37].

Figure 7 presents the effect of the diols on the evolution of the gel content during the polymerizations carried out with polyurethane in the formulation. The effect of the diols was much less pronounced than in the case of the all acrylic formulations (Figure 5). The diols affected the polymer microstructure in two ways. Firstly, acting as a chain transfer agent, they reduced the kinetic chain length of the acrylic chains. Secondly, through the reaction with the isocyanate groups of the Incorez 701, they affected the length of the polyurethane chains and the number of isocyanate groups able to react with 2-HEMA, which in turns, affected the number of PU/acrylic linking points. 


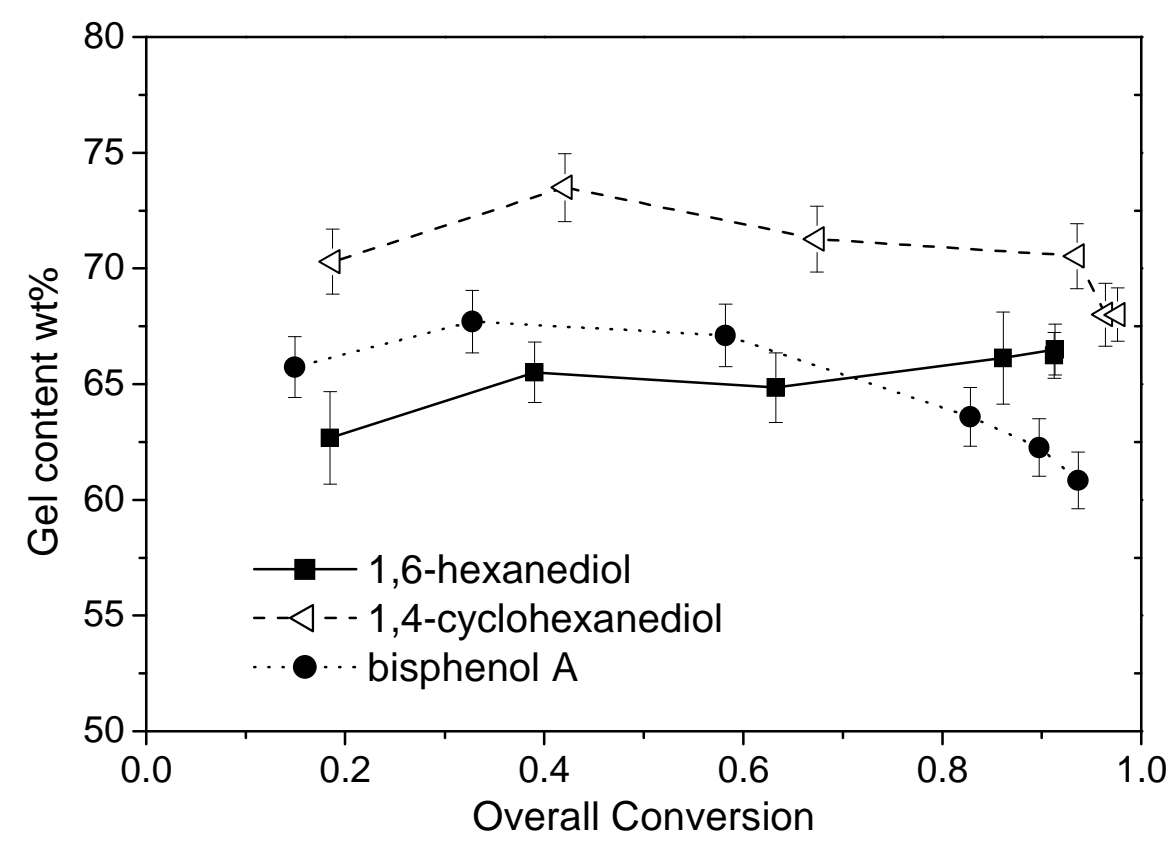

Figure 7. Effect of the diol on the evolution of the gel content of hybrid formulations.

The activity of the diols as chain transfer agent decreased from bisphenol A, to 1,4cyclohexanediol and to 1,6-hexanediol. Therefore, the kinetic chain length of the acrylic chains should follow the following order: $\lambda_{\text {bisphenol A }}<\lambda_{1,4-\text { cyclohexanediol }}<\lambda_{1,6-\text { hexanediol. }}$ Assuming that the 2 HEMA units were randomly distributed through the acrylic chains, the shorter the kinetic chain length of the acrylic polymer, the less likely it is that the chain becomes linked to polyurethane (because it has a lower number of possible linking points, i.e., 2-HEMA units). Therefore, without further consideration, one would expect the gel content to decrease from 1,6-hexanediol to 1,4cyclohexanediol and to bisphenol A. However, this is not what was observed in Figure 7. The reason is the effect of the diols on the reaction between the hydroxyl groups of the 2-HEMA units and the isocyanate groups of Incorez 701. The higher that the relative reactivity of the diol with the isocyanate with respect to that of the 2-HEMA is, then the lower is the probability of polyurethane incorporation into the acrylic chain, and therefore, the lower is the probability of crosslinking.

The reactivity of alcohols with the isocyanate group depends on their chemical structure. Primary alcohols are the most reactive ones, followed by secondary and aromatic alcohols [39]. Therefore 1,6-hexanediol and 2-HEMA had a similar reactivity, 1,4-cyclohexanediol had a slightly lower 
reactivity than 2-HEMA, and bisphenol A was less reactive than 2-HEMA. According to these relative reactivity values, the probability of reaction of Incorez 701 with 2 -HEMA decreased from bisphenol A, to 1,4-cyclohexanediol, and to 1,6-hexanediol. This counteracted the effect of the diols on the length of the acrylic chains, yielding relatively similar gel contents for the three diols.

When bisphenol A was used, due to its high activity as chain transfer agent and to the low reactivity with respect to the isocyanate group, the polymer of the gel was most likely formed by relatively short acrylic chains linked by many relatively short polyurethane chains. The contribution of the pure acrylic network was, most likely, negligible. (This conclusion is supported by the results in Figure 5, which show that in the presence of bisphenol A no gel was formed in an all-acrylic miniemulsion polymerization.) In essence, the PU acted as a crosslinker for an uncrosslinked acrylic polymer.

When 1,6-hexanediol was used, due to its low efficiency as a chain transfer agent and its high reactivity with isocyanate groups, the polymer of the gel was most likely formed by long acrylic chains linked by a relatively low number of extended polyurethane chains.

For 1,4-cyclohexanediol, the gel was formed by relatively long acrylic chains linked by both polyurethane chains and pure acrylic chains, which may be the reason for the higher gel content (Figure 7).

Some information about the network density can be obtained from the swelling measurements and the average molecular weights between crosslinking points, $M_{\mathrm{c}}$, estimated from them. Table 3 shows that the polymer synthesized with bisphenol A was less densely crosslinked than those prepared using 1,6-hexanediol and 1,4-cyclohexanediol, most likely due to the contribution of acrylic crosslinks to the formation of the network in the latter cases. 1,4-cyclohexanediol was slightly less densely crosslinked than 1,6-hexanediol, probably due to the contribution of the PU type connections to gel formation. Schematic diagrams representing the polymer networks, as deduced from the analysis, are presented in Figure 8. It is worth pointing out that no phase separation within the hybrid particles was observed in AFM analysis, as is shown in the images of particles synthesized with bisphenol A in Figure 9. The phase contrast at the particle peripheries is attributed 
to a greater AFM tip interaction with the mica substrate because the particles are soft (i.e. at temperatures well above their glass transition temperature), they spread on the mica substrate and consequently, the thickness is lower near the particle edges. Hence, the phase shift is likely to be caused by the substrate. Images of all-acrylic particles were similar.

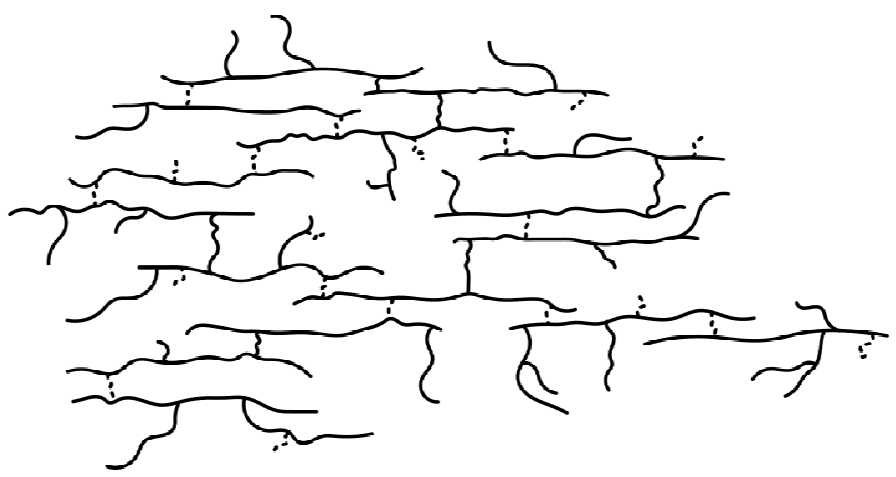

(a) Bisphenol A

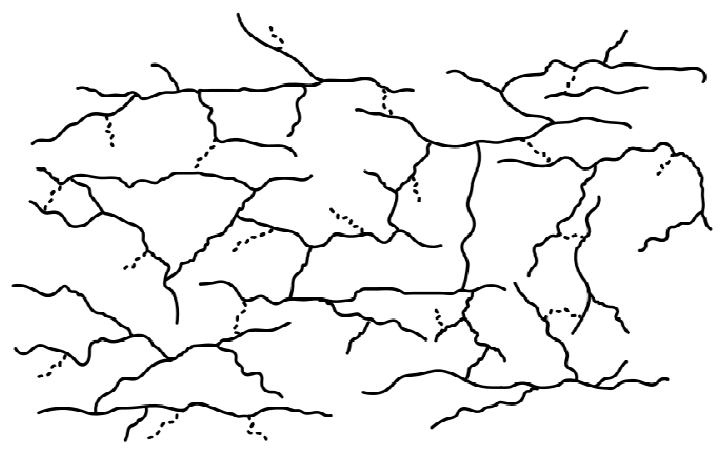

(b) 1,4-cyclohexanediol

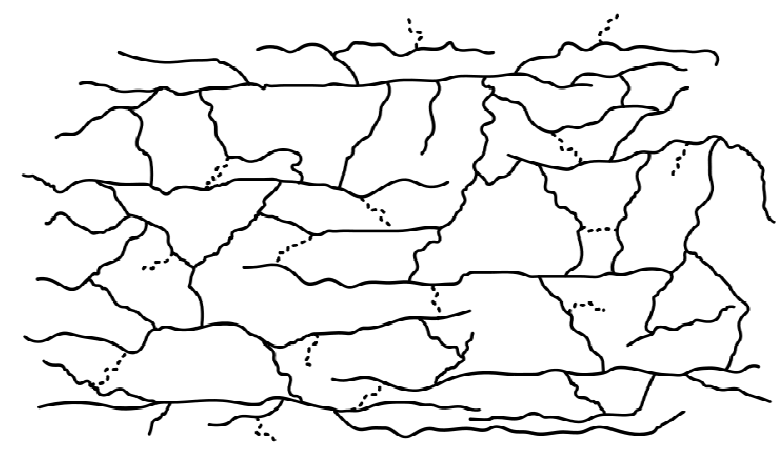

(c) 1,6-hexanediol

Figure 8. Schematic diagrams of the gel networks for the different diols. Solid lines represent the acrylic chains and dashed lines the polyurethane chains. 

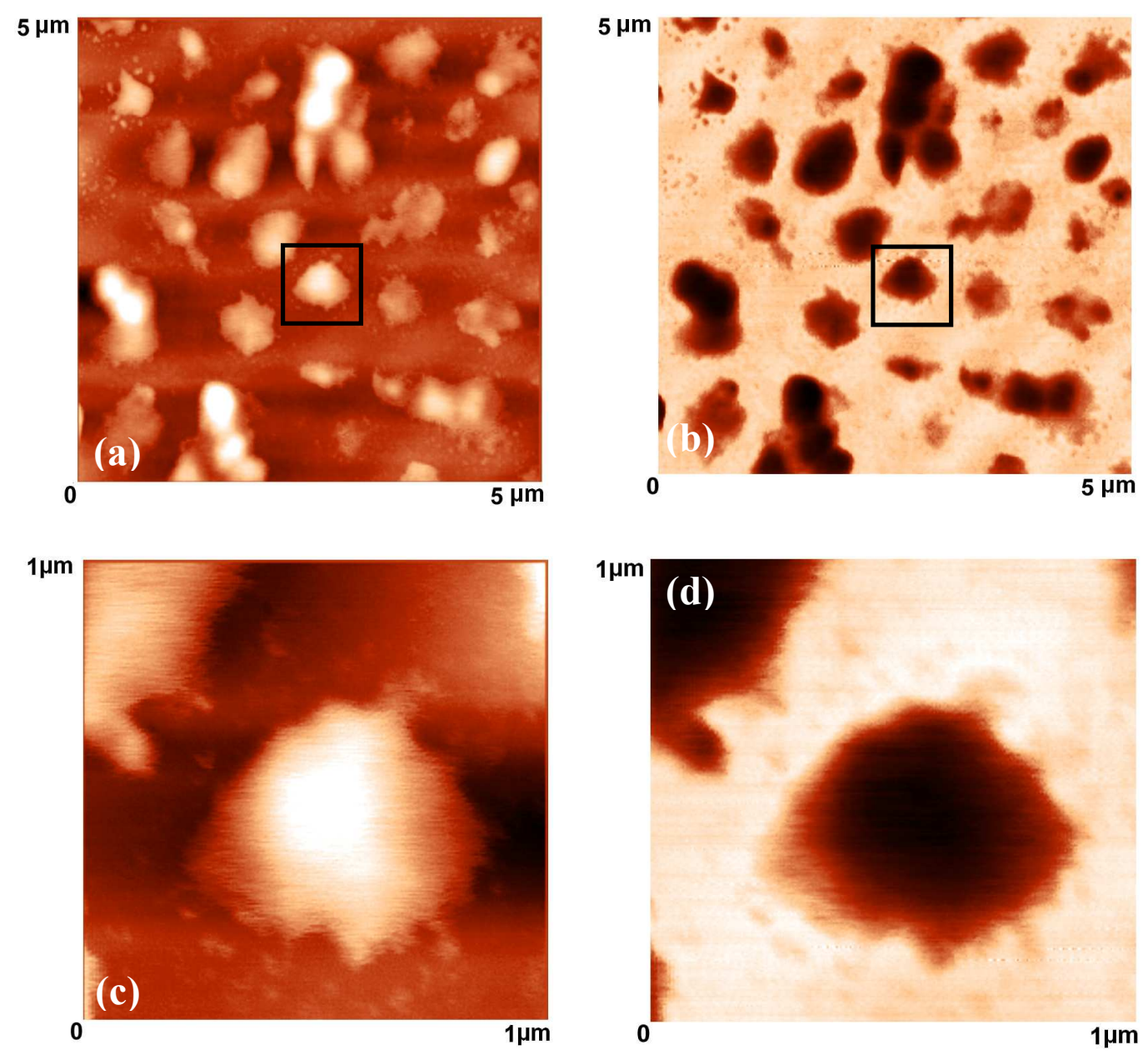

Figure 9. AFM images of individual particles of the hybrid latex synthesized with bisphenol A, deposited on a mica substrate. (a) Height image (0-285 nm range) and (b) phase image (82-98 range) are shown for a $5 \mu \mathrm{m} \times 5 \mu \mathrm{m}$ area. The zone shown with the squares are presented in higherresolution $(1 \mu \mathrm{m} \times 1 \mu \mathrm{m})$ in a (c) height image (0-152 $\mathrm{nm}$ range) and (d) phase image $\left(85-97^{\circ}\right.$ range)

The evolution of sol molecular weight during the process of the latexes formulated with different chain extenders is presented in Figure 10. The evolution of the weight average molecular weight was similar to that found in the absence of PU (Figure 6), although lower sol molecular weights were obtained in the present case. The lower molecular weights were due to the preferential incorporation of longer chains in the gel (which was more acute in the presence of Incorez 701). The sharp decrease of the $\overline{M_{w}}$ for the reactions carried out with 1,6-hexanediol and 1,4-cyclohexanediol was 
due to the contribution of pure acrylic connections to gel formation, which resulted in a continuous incorporation of long acrylic chains to gel throughout the whole process [40].

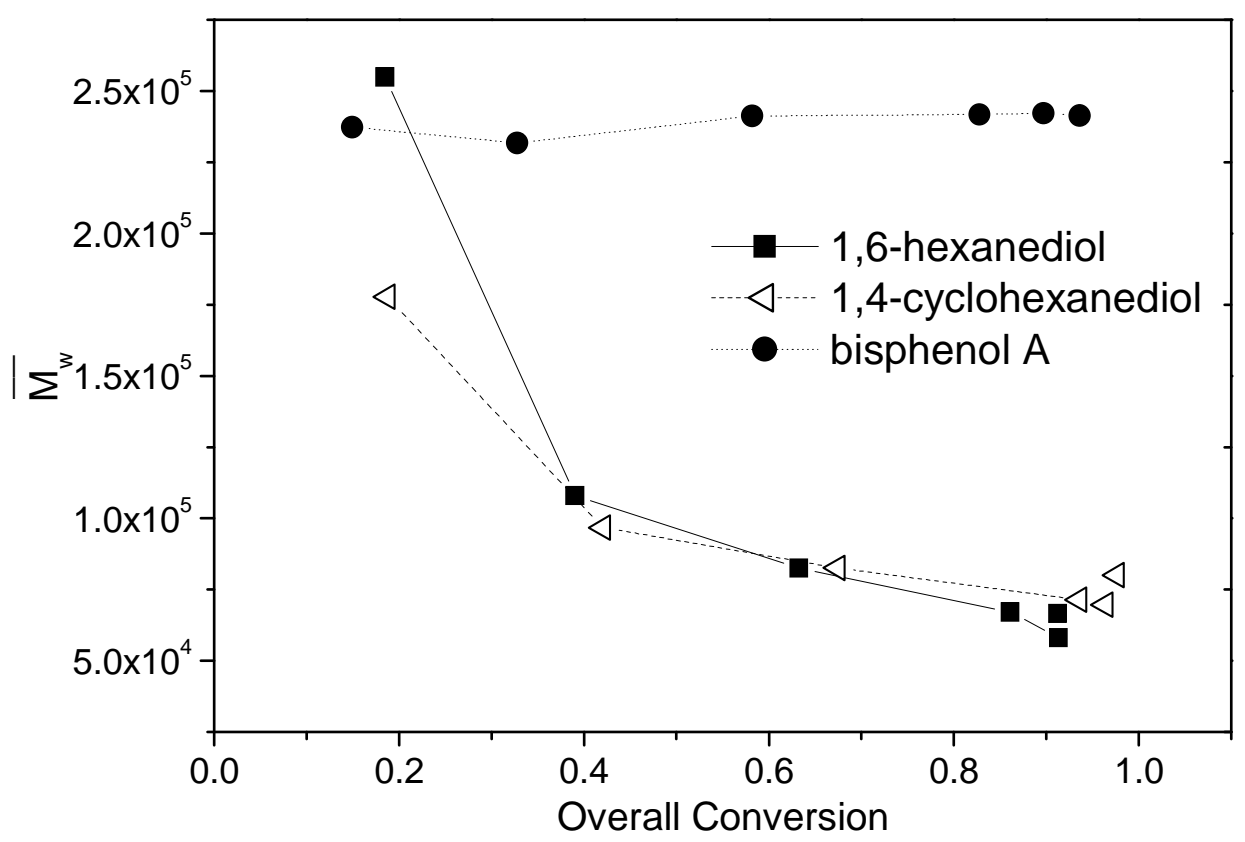

Figure 10. Effect of the diol on the sol weight average molecular weight of hybrid formulations.

On the other hand, the evolution of sol molecular weight in the polymerization carried out with bisphenol A was interesting because it did not vary during the process. In this case, the contribution of acrylic connections to the formation of gel was minor (no gel was formed in the absence of Incorez 701, Figure 5), therefore, the constant $\overline{M_{w}}$ has to be related to the addition polymerization. Longer acrylic chains contained a higher number of 2-HEMA units. Therefore, in principle, they should be preferentially incorporated into the gel, which would lead to a decrease in the molecular weight of the soluble fraction. The fact that in the experiments carried out with PU prepolymer, the sol molecular weight (Figure 10) was lower than in the absence of PU (Figure 6) shows that this actually occurred. However, contrary to what occurs when the gel is formed through acrylic connections (intermolecular chain transfer coupled with termination by combination), in each particle, gel was not continuously formed during the process, but gel formation ended when the isocyanate groups of the PU prepolymer contained in that particle totally reacted. The reason was that as Incorez 701 is water insoluble, it was not transported from the entering droplets to the 
existing particles, and hence, once the isocyanate groups of the Incorez 701 contained in a given particle reacted, the addition polymerization in that particle stopped, and also did the gel formation process.

\subsection{Adhesive properties}

Table 3 summarizes the effect of the microstructure of the polyurethane/acrylic hybrid nanoparticles on the adhesive properties. The results obtained with the all-acrylic formulation are included as a reference.

Table 3. Effect of the diol on polymer microstructure and adhesive properties.

\begin{tabular}{|c|c|c|c|c|c|c|c|c|c|}
\hline $\begin{array}{c}\text { Incorez } \\
701 \\
\text { wt } \%\end{array}$ & Chain extender & $\begin{array}{c}\text { Gel } \\
\text { content } \\
\text { wt } \%\end{array}$ & $\begin{array}{l}\text { Swelling } \\
\text { capability }\end{array}$ & $\begin{array}{c}\mathrm{M}_{\mathrm{c}} \\
\left(10^{4}\right. \\
\mathrm{g} / \mathrm{mol})\end{array}$ & $\begin{array}{c}\overline{M_{w}} \\
\left(10^{4}\right. \\
\mathrm{g} / \mathrm{mol})\end{array}$ & $\begin{array}{c}\text { Shear } \\
\text { resistance } \\
\mathrm{SS} \mathrm{T}=70^{\circ} \mathrm{C}\end{array}$ & $\begin{array}{l}\text { SAFT } \\
\left({ }^{\circ} \mathrm{C}\right)\end{array}$ & $\begin{array}{c}\text { Peel } \\
\text { resistance } \\
(\mathrm{N} / 25 \mathrm{~mm})\end{array}$ & $\begin{array}{l}\text { Loop tack } \\
(\mathrm{N} / 25 \mathrm{~mm})\end{array}$ \\
\hline 9.65 & 1,6-hexanediol & $66.2 \pm 1.1$ & $18 \pm 3$ & 4.5 & 6.6 & $\begin{array}{c}0.18 \pm 0.04 \\
\text { minutes } \\
(\mathrm{A})^{*}\end{array}$ & $72 \pm 1$ & $\begin{array}{c}2.9 \pm 0.9 \\
(\mathrm{~A})^{*}\end{array}$ & $\begin{array}{c}5.1 \pm 0.8 \\
(\mathrm{~A})^{*}\end{array}$ \\
\hline 9.65 & $\begin{array}{c}1,4- \\
\text { cyclohexanediol }\end{array}$ & $68.0 \pm 1.2$ & $23 \pm 8$ & 6.9 & 8.0 & $\begin{array}{c}7.12 \pm 2.8 \\
\text { minutes } \\
(\mathrm{A})^{*}\end{array}$ & $71 \pm 2$ & $\begin{array}{c}2.8 \pm 0.2 \\
(\mathrm{~A})^{*}\end{array}$ & $\begin{array}{l}4.7 \pm 1.0 \\
(\mathrm{~A})^{*}\end{array}$ \\
\hline 9.65 & bisphenol A & $60.8 \pm 1.2$ & $26 \pm 6$ & 8.6 & 21.4 & $\begin{array}{c}>65 \text { hours } \\
\text { without } \\
\text { failure }\end{array}$ & $>210$ & $\begin{array}{c}3.9 \pm 0.1 \\
(\mathrm{~A})^{*}\end{array}$ & $\begin{array}{c}4.0 \pm 0.5 \\
(\mathrm{~A})^{*}\end{array}$ \\
\hline 0 & None & $73.4 \pm 1.5$ & $17 \pm 4$ & 4.0 & 17.6 & $\begin{array}{c}0.04 \pm 0.005 \\
\text { minutes } \\
(\mathrm{C})^{*}\end{array}$ & $137 \pm 2$ & $\begin{array}{c}4.1 \pm 0.2 \\
(\mathrm{~A})^{*}\end{array}$ & $\begin{array}{c}3.2 \pm 0.4 \\
(\mathrm{~A})^{*}\end{array}$ \\
\hline
\end{tabular}

* (A) Adhesive type failure. (C) Cohesive type failure.

It can be seen that shear resistance and SAFT (which are related to the ability of the polymer to stay adhered to a substrate as the temperature is increased [41]) were much higher when bisphenol A was used. Both the all-acrylic formulation and the hybrid with 1,6-hexanediol or 1,4cyclohexanediol performed much worse in this test of durability but for very different reasons. 
The all-acrylic formulation failed cohesively in the bulk of the adhesive layer. Because the gel content in the all-acrylic was high and the equilibrium swelling was relatively low (i.e. the network was quite dense), this low cohesive strength strongly suggests that the interfaces between particles are, in this case, the weak points of the system. (It has been shown previously that restricted chain interdiffusion between crosslinked particles results in weaker latex films, because of fewer entanglements across the interfaces [42].) This in turn suggests that the presence of the PU reinforced the interfaces between particles in the hybrid formulation, and that made the PSA film more cohesive through hydrogen bonding between particles, namely, the type of bonding often provided by carboxylic groups $[43,44]$. On the other hand, the low shear resistance of PSAs synthesized with 1,6-hexanediol and 1,4-cyclohexanediol cannot be attributed to the presence of weak interfaces, because the failure is here clearly interfacial. In this case, the PSA detaches early because the materials are too elastic, which favors crack propagation at the adhesive-substrate interface. This is consistent with the very low $\mathrm{Mw}$ of the sol fraction combined with the high gel fraction (Figures 7 and 10) obtained with these diols.

Large-strain stress/strain measurements were used in order to describe the response of the materials further and to provide evidence for the weaker particle-particle interfaces of the all-acrylic formulation. Because the hybrid formulation containing bisphenol A was presenting the best adhesive performance, both the PU/acrylic hybrid obtained with bisphenol A and the all-acrylic formulations were compared. The stress/strain curves are presented in Figure 11. 


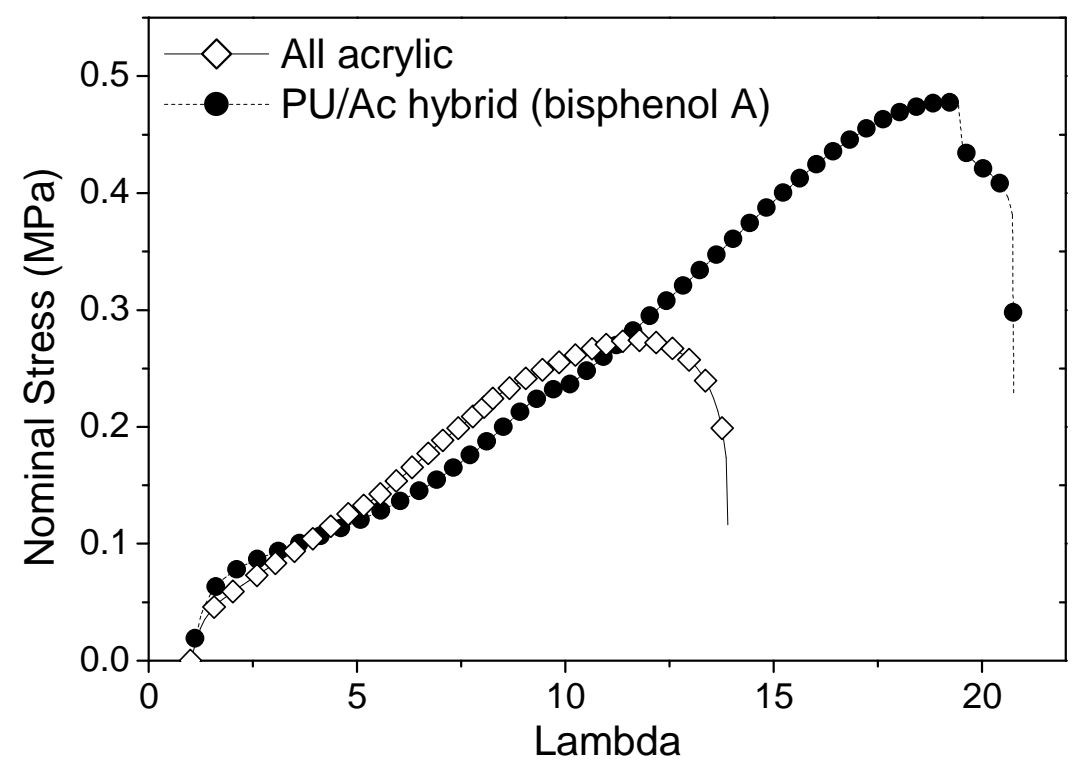

Figure 11. Comparison of the large strain behavior between the all acrylic and the PU/acrylic hybrid formulated with bisphenol A.

It can be seen that, while the curves are fairly similar, two important differences clearly appear: First, at very large strains, the failure strain of the hybrid film was much higher than that of the allacrylic, which can only be attributed to weaker interfaces between particles in the latter case. Second, at small strains, the hybrid is stiffer while it softens markedly at intermediate strains. That is a signature of a more viscoelastic behavior at large strain and leads to higher shear resistance [45]. Even if the absolute values of tack and peel resistance obtained were low, mainly because of an over-crosslinking of the gel network, differences in both the gel and the sol fractions still had a slight effect on the final peel and tack values. The higher sol molecular weight and the more viscoelastic film obtained for bisphenol A led to a system which was both stiffer than the all acrylic and able to dissipate more energy upon deformation, leading to slightly higher peel values but most importantly to much higher values of long-term shear resistance. In fact, small strain measurements in which the all acrylic and the PU/acrylic hybrid containing bisphenol A were compared (Figure 12) indicate that the hybrid formulation was stiffer than the all acrylic formulation while keeping the same $\tan \delta$. This leads to a significantly higher value of $\tan \delta / G^{\prime}$ which has been demonstrated in similar systems to give a higher adhesion energy $[46,47]$. On the other hand, the much lower sol molecular weights 
obtained for 1,4-cyclohexanediol and 1,6-hexanediol helped to create a fast molecular contact, leading to slightly higher tack values. The rigidity that the bisphenol A provided to the polymer may also contribute to the lower tack value.

(a)

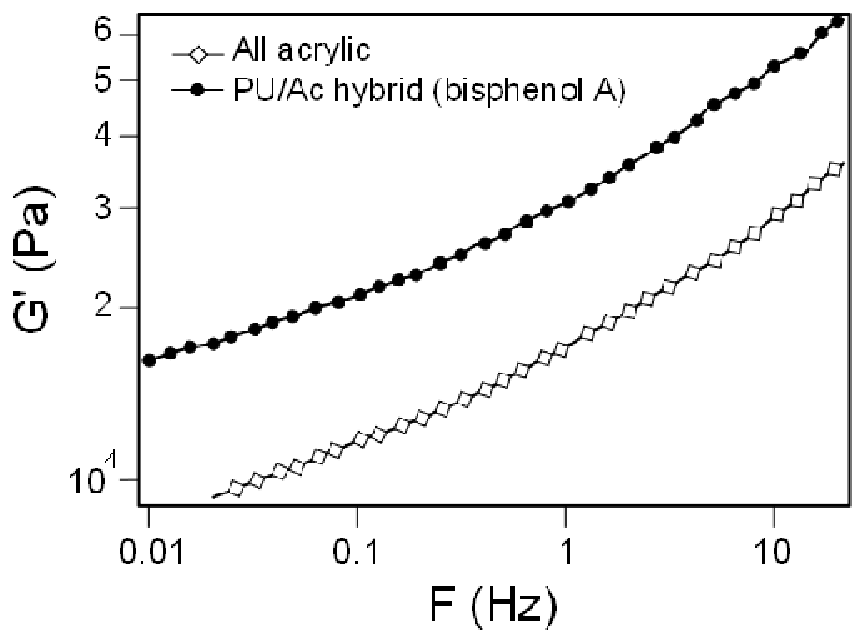

(b)

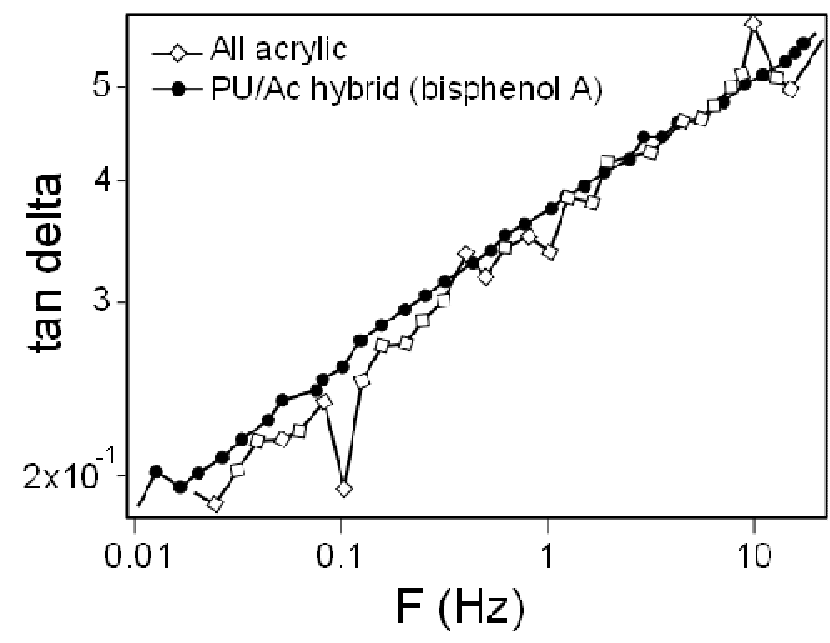

Figure 12. Comparison of the rheological properties, G' (a) and tan $\delta$ (b) between the all acrylic and the PU/acrylic hybrid formulated with bisphenol A.

\section{Conclusions}

In the foregoing, the microstructure of PU/acrylic PSAs was modified by altering the polyurethane chain using different diols. It was found that the nature of the diols affected the polymerization rate $\left(R_{p}\right)$, because the diols are efficient chain transfer agents. The effect on $R_{p}$ was stronger as the stability of the radical formed and its water solubility increased. Therefore, $R_{p}$ decreased as $1,4-$ cyclohexanediol $>$ 1,6-hexanediol $>$ bisphenol A. The type of diol had a modest effect on the gel content, but a strong effect on the type of the network formed. Because of their combined effect on both the kinetic chain length of the acrylic chains and the number of PU/acrylic linking points, different types of networks were formed. Bisphenol A promoted a network formed by relatively short acrylic chains linked by many relatively short polyurethane chains. 1.6-hexanediol yielded a gel formed by long acrylic chains linked by a relatively low number of chain extended polyurethane chains. 1,4-cyclohexanediol led to a gel in which the links were due to both polyurethane chains and pure acrylic connections. The gel produced with bisphenol A was overall less densely crosslinked 
than the gels produced with the other diols. The microstructure of the gel had a very strong effect on the shear resistance and on the SAFT. The gel produced with bisphenol A gave a much better resistance to shear than those produced with other diols, probably due to its better combination of significant crosslinking density and reasonable viscoelasticity. This led to a substantially higher shear resistance and SAFT value. The differences in peel resistance and tack were modest.

As a general conclusion, our study emphasizes that a good shear resistance for PSA is not only related to the gel fraction but to the detailed microstructure of the gel. Although the importance of the connectivity between particles had already been demonstrated for both hydrogen $[43,44]$ and covalent $[48,49]$ bonding we show here conclusively that even inside each particle, identical levels of gel can lead to vastly different adhesive properties if the architecture of the network is different. Synthetic tools providing control over this microstructure in detail hold great promise for the design of novel adhesives with a better balance of properties.

\section{Acknowledgments}

A.L. acknowledges the fellowship by the Basque Government ("Ikertzaileak Prestatzeko eta Hobetzeko Beken Programak"). The financial support of the European Commission (NAPOLEON NMP3-CT-2005-011844) is gratefully acknowledged. The authors want to thank to Dr. Mikel Gaztelumendi and Mr. Asier Zabaleta for the help in loop tack and peel resistance measurements.

\section{References}

1. Creton C. MRS Bulletin 2003;28:434-439.

2. Everaerts AI, Clemens LM. Pressure-Sensitive Adhesives. In: Chaudhury M and Pocius AV, editors. Adhesion Science and Engineering - 2. Surfaces, Chemistry and Applications. Amsterdam: Elsevier, 2002. pp. 465-534.

3. Jovanovic R, Dubé MA. Polym. Rev. 2004;44:1-51. 
4. Dehnke MK. Adhes. Age 1994;37:12-13.

5. Tobing SD, Klein A. J. Appl. Polym. Sci. 2001;79:2230-2244.

6. Benedek I. Pressure-Sensitive Formulation. Utrech: VSP, 2000.

7. Satas D. Acrylic adhesives. In: Satas D, editor. Handbook of Pressure-Sensitive Adhesive Technology. New York: Van Nostrand Reinhold, 1989. pp. 396-456.

8. Kukanja D, Golob J, Valant AZ, Krajnc M. J. Appl. Polym. Sci. 2000;78:67-80.

9. Chen S, Chen L. Colloid Polym. Sci. 2003;282:14-20.

10. Brown RA, Coogan RG, Fortier DG, Reeve MS, Rega JD. Prog. Org. Coat. 2005;52:73-84.

11. Wang C, Chu F, Guyot A, Gauthier C, Chapel JP. Polymer 2005;46:1113-1124.

12. Hirose M, Kadowaki F, Zhou J. Prog. Org. Coat. 1997;31:157-169.

13. Gooch JW, Dong H, Schork JF. J. Appl. Polym. Sci. 2000;76:105-114.

14. Zhang HT, Guan R, Yin ZH, Lin LL. J. Appl. Polym. Sci. 2001;82:941-947.

15. Barrère M, Landfester K. Macromolecules 2003;36:5119-5125.

16. Li D, Daniels ES, Dimonie V, Sudol ED, El-Aasser MS. Macromolecules 2005;38:41834192.

17. Lu Y, Larock RC. Biomacromolecules 2007;8:3108-3114.

18. Chauvet J, Asua JM, Leiza JR. Polymer 2005;46:9555-9561. 
19. Qie L, Dubé M. Macromol. React. Eng. 2011;5:117-128.

20. Kim BK. Colloid Polym. Sci. 1996;274:599-611.

21. Jhon Y-K, Cheong I-W, Kim J-H. Colloids Surf., A 2001;179:71-78.

22. Chen KL, Chen W-T. U.S. Patent 6,191,214, 2001.

23. Li CY, Chiu WY, Don TM. J. Polym. Sci., Part A: Polym. Chem. 2005;43:4870-4881.

24. Frisch KC, Rumao LP. J. Macromol. Sci., Rev. Macromol. Chem. 1970;5:103-149.

25. Higuchi WI, Misra J. J. Pharm. Sci. 1962;51:459-466.

26. Flory PJ., Rehner J. J. Chem. Phys. 1943; 11: 521-526.

27. Flory, P. J. Principles of Polymer Chemistry. Cornell University Press: Ithaca, NY, 1953.

28. Bandrup J., Immergut E. H., Grulke E. A., Bloch, D. Polymer Handbook. WileyInterscience: Hoboken, NJ, 1999.

29. FTM 9. Loop tack measurement. FINAT Technical Handook. The Hague: FINAT, 2005.

30. FTM 1. Peel adhesion $\left(180^{\circ}\right)$ at $300 \mathrm{~mm}$ per minute. FINAT Technical Handbook. The Hague: FINAT, 2005.

31. FINAT. FTM 8. Resistance to shear from a standard surface. FINAT Technical Handbook. The Hague: FINAT, 2005.

32. Grassl B, Alb AM, Reed WF. Macromol. Chem. Phys. 2001;202:2518-2524.

33. Liu X, Chen D, Yue Y, Zhang W, Wang P. J. Appl. Polym. Sci. 2006;102:3685-3690. 
34. Ochoa-Gomez JR, Escudero-Sanz FJ, Sasia PM, Rio F, Nieto-Mestre J, Torrecilla J, Katime IA. J. Appl. Polym. Sci. 2009;114:2673-2684.

35. Kadoma Y, Fujisawa S. Biomaterials 2000;21:2125-2130.

36. Kong L, Wang L-F, Zhang H-Y. THEOCHEM 2005;716:27-31.

37. Plessis C, Arzamendi G, Leiza JR, Schoonbrood HAS, Charmot D, Asua JM. Macromolecules 2000;33:5041-5047.

38. Plessis C, Arzamendi G, Leiza JR, Alberdi JM, Schoonbrood HAS, Charmot D, Asua JM. J. Polym. Sci., Part A: Polym. Chem. 2001;39:1106-1119.

39. Vilar WD. Chemistry and Technology of Polyurethanes. Rio de Janeiro: Vilar Consultoria, Ltda., 2002.

40. Gonzalez I, Leiza JR, Asua JM. Macromolecules 2006;39:5015-5020.

41. Benedek I, Heymans LJ. Adhesive performance characteristics. Pressure-Sensitive Adhesives Technology. New York: Marcel Dekker Inc., 1997.

42. Zosel A and Ley G. Macromolecules 1993;26:2222-2227.

43. Garret J., Lovell P. A., Shea J. A., Viney R. D. Macromol. Symp. 2006; 151: 487-496.

44. Urban, D., Egan, L. Applications in the adhesives and construction industries. In Polymer Dispersions and Their Industrial Applications; Urban, D., Takamura, K., Eds.; Wiley-VCH: Weinheim, 2002; 191-253.

45. Bellamine A, Degrandi E, Gerst M, Stark R, Beyers C, Creton C. Macromol. Mater. Eng. $2011 ; 296: 31-41$. 
46. Deplace F, Carelli C, Mariot S, Retsos H, Chateauminois A, Ouzineb K, Creton C. J. Adhes. 2009;85:18-54.

47. Wang T, Lei CH, Dalton AB, Creton C, Lin Y, Fernando KAS, Sun YP, Manea M, Asua JM, Keddie JL. Adv. Mater. 2006;18:2730-2734.

48. Deplace F, Carelli C, Langenfeld A, Rabjohns MA, Foster AB, Lovell PA, Creton C. ACS Appl. Mater. Interfaces 2009;1:2021-2029.

49. Deplace F, Rabjohns MA, Yamaguchi T, Foster AB, Carelli C, Lei C-H, Ouzineb K, Keddie JL, Lovell PA, Creton C. Soft Matter 2009;5:1440-1447. 
For Table of Contents use only

Simultaneous Free Radical and Addition Miniemulsion Polymerization: Effect of the Diol on the Microstructure of Polyurethane-Acrylic Pressure-Sensitive Adhesives.

Aitziber Lopez, Elise Degrandi, Costantino Creton, José M. Asua

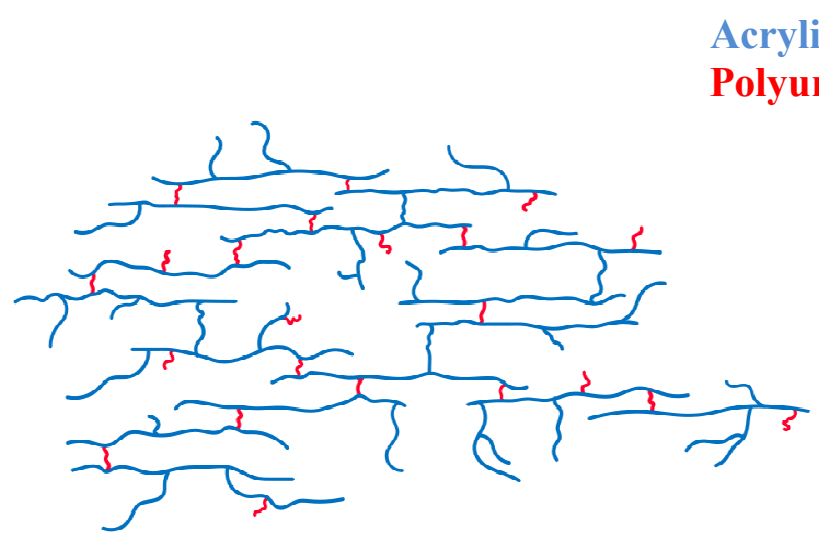

Bisphenol A

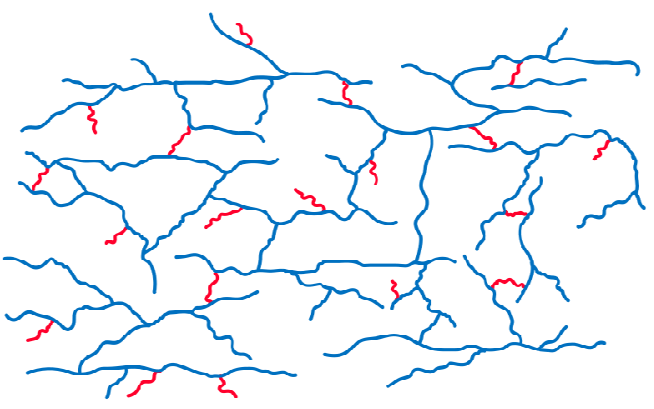

1,4-cyclohexanediol

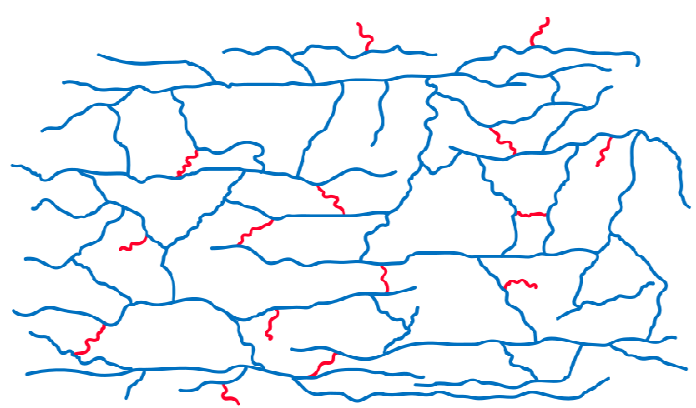

1,6-hexanediol 